\title{
VERIFICATION OF MCD19A2 DATA AND STUDY OF AEROSOL CHARACTERISTICS IN BEIJING-TIANJIN-HEBEI REGION
}

\author{
Chen Jia $^{1,}$, Lin Sun ${ }^{1}$, Xikong Zhang ${ }^{1}$, Yongji Wang ${ }^{1}$ \\ ${ }^{1}$ Geomatics College, Shandong University of Science and Technology, Qingdao, China - jiachen_1991@163.com
}

KEY WORDS: Atmospheric aerosol, Aerosol Optical Depth, MCD19A2, Verification, Aerosol characteristics, Beijing-TianjinHebei region

\begin{abstract}
:
The atmospheric aerosol pollution in the Beijing-Tianjin-Hebei(BTH) region of China is particularly serious. To quickly and accurately evaluate the aerosol pollution in BTH region using the remote sensing method - this article verified the accuracy of the global 1 km resolution MCD19A2 aerosol optical depth (AOD) product to clarify its reliability in BTH region, moreover, MCD19A2 was used to study the characteristics of aerosols and its correlation with air quality index (AQI). First, the AOD spatial distribution in BTH region from 2014 to 2018 was obtained through the processes of MCD19A2 such as format conversion, mosaic. Then the AOD results were verified with AERONET measured data through accurate space-time matching, proving the high accuracy and reliability of MCD19A2 $(R=0.9504, M A E=0.0863, R M S E=0.1243, E E=82.26 \%)$. Besides, based on the AOD results at different scales, the spatiotemporal characteristics of aerosols in BTH region were analyzed from the aspects of spatial distribution, annual variation, and seasonal variation. Finally, the study shows that MCD19A2 AOD and AQI have a high correlation and similar spatiotemporal characteristics, proving the direct indication of MCD19A2 on air pollution. This article plays an important role in the research of aerosol characteristics, air pollution monitoring and so on.
\end{abstract}

\section{INTRODUCTION}

Due to economic development and dense population, the emission of air pollutants such as aerosols in BTH region is increasing rapidly (Wang et al. 2018). Moreover, sea-land breeze and topography cause the difficult diffusion and cyclic accumulation of pollutants. (Bei et al. 2018). The severe air pollution, especially aerosol pollution, has direct effects on climate change and human health (Charlson et al. 1992; Sokolik et al. 1996). Therefore, monitoring and studying the characteristics of aerosol pollution accurately in BTH region is of great significance to analyze climate change, urban air quality and other issues.

Satellite remote sensing plays an important role in aerosol monitoring due to large-scale observation, long time series, and short update periods (Kaufman et al. 1988). The MODIS sensor provides a good data basis for aerosol research in different regions with a long time series of global aerosol observation data (Sayer et al. 2014). MCD19A2 is the latest MODIS C6 aerosol data released by NASA, which uses the Multi-Angle Implementation of Atmospheric Correction (MAIAC) algorithm (Lyapustin et al. 2011) to produce daily global aerosol products with a spatial resolution of $1 \mathrm{~km}$. Based on time series analysis and image processing, the MAIAC algorithm achieves AOD inversion through the calculation of the Bidirectional Reflectance Distribution Function (BRDF) and Spectral Regression Coefficient (SRC). The MAIAC algorithm has cloud masks (Lyapustin et al. 2008), dynamic land-water-snow classification and surface type coverage (Lyapustin et al. 2009), which can be applied for different land surfaces to achieve aerosol inversion. The research (Chudnovsky et al. 2013) proves that MAIAC has higher aerosol inversion accuracy than MOD04 on the brighter surface. MCD19A2 realizes high-precision and high-resolution aerosol inversion and meets different application requirements such as air quality analysis.

The high heterogeneity in BTH region poses a huge challenge to the accuracy of aerosol inversion (Wei et al. 2016). First, due to the complex surface types and the low density of dark vegetation in this region, the land surface reflectance is high and it is difficult to effectively separate the atmosphere and surface information. At the same time, the sources and types of aerosols in this region are relatively complex. Therefore, it is necessary to verify the accuracy, reliability and applicability of MCD19A2 in BTH region.

The researches (Bilal et al. 2016; Xie et al. 2011; Wong et al. 2013) have used aerosol ground observation data such as AErosol RObotic NETwork (AERONET) to verify various aerosol products in different regions, which is of great significance in assessment and study of aerosol products. BTH region was selected as the study area in this article. Using remote sensing methods, we carry out verification of MCD19A2 AOD, and explore the aerosol characteristics and the correlation between $\mathrm{AOD}$ and $\mathrm{AQI}$ in $\mathrm{BTH}$ region.

\section{STUDY AREA AND DATA}

\subsection{Study area}

BTH region $\left(36^{\circ}-42^{\circ} \mathrm{N}, 112^{\circ}-121^{\circ} \mathrm{E}\right)$ is located in eastern China, with complex terrain and typical temperate continental monsoon climate. Due to the severe air pollution, it has become a hot region for environmental researches such as aerosol monitoring and air pollution evaluation (Wang et al. 2015). Therefore, BTH region was selected as the study area in this article. Figure 1

\footnotetext{
* Corresponding author
} 
shows the geographical location and administrative divisions of BTH region, including 13 cities.

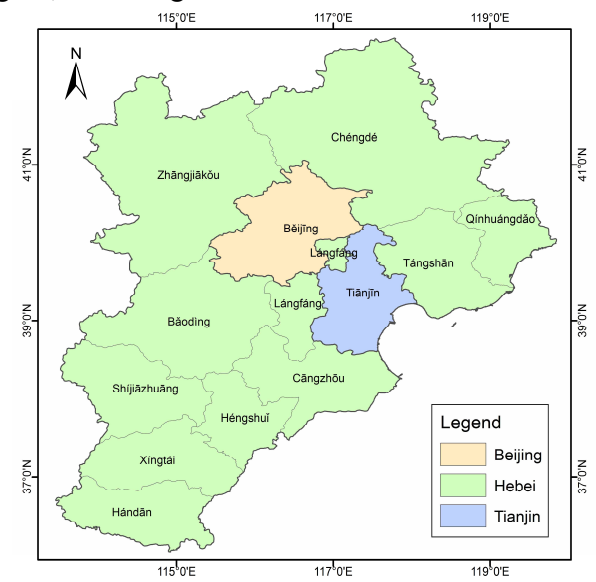

Figure 1. Geographic location and administrative divisions of BTH region

\subsection{Data and process}

\subsubsection{MCD19A2}

MCD19A2 is the MODIS C6 aerosol product released by NASA, including AOD at 550nm, asymmetry factor, etc. The MCD19A2 data covering BTH region from 2014 to 2018 , a total of 7176 scenes in HDF format, were selected to produce $550 \mathrm{~nm}$ AOD for aerosol research.

The processes of MCD19A2 include image format conversion, invalid values removal, mosaic and cropping. Format conversion refers to converting HDF format data into Tiff images and assigning projection information; invalid values removal refers to excluding the pixels greater than two in the AOD images; mosaic refers to stitching the images into a whole image covering BTH region; cropping refers to crop the whole image using the vector to obtain BTH region image. Through the processes, the daily AOD spatial distribution in $\mathrm{BTH}$ region was obtained with a spatial resolution of $1 \mathrm{~km}$.

\subsubsection{AERONET}

AERONET is a ground-based remote sensing aerosol network established by NASA and PHOTONS to provide aerosol ground-based measurements in major regions of the world. It provides the measured values of AOD at $440 \mathrm{~nm}, 675 \mathrm{~nm}$, $870 \mathrm{~nm}$ and $1020 \mathrm{~nm}$ with a time resolution of 15 minutes. To ensure the reliability of the aerosol research and characterization, the AERONET measured data of 6 sites in 2014 in BTH region was selected to verify the accuracy of MCD19A2 AOD at 550nm. The information of the selected AERONET data is shown in Table 1.

\begin{tabular}{ccccc}
\hline Number & Site name & $\begin{array}{c}\text { Longitude } \\
\left({ }^{\circ} \mathrm{E}\right)\end{array}$ & $\begin{array}{c}\text { Latitude } \\
\left({ }^{\circ} \mathrm{N}\right)\end{array}$ & Level \\
\hline 1 & Beijing & 116.3814 & 39.9769 & 2.0 \\
2 & $\begin{array}{c}\text { Beijing- } \\
\text { CAMS }\end{array}$ & 116.3167 & 39.9333 & 2.0 \\
3 & $\begin{array}{c}\text { Beijing_RADI } \\
\text { Shijiazhuang- } \\
\text { SZF }\end{array}$ & 116.3786 & 40.0048 & 1.5 \\
5 & $\begin{array}{c}\text { Shijiazhuang- } \\
\text { CHEY }\end{array}$ & 114.5583 & 38.0167 & 1.5 \\
6 & XiangHe & 116.9615 & 39.0000 & 1.5 \\
\hline
\end{tabular}

Table 1. Sites and data information of AERONET
Since the $550 \mathrm{~nm}$ AOD measurement is not provided by AERONET, the Angstrom formulas (Equation 1-3) are used to perform band conversion.

$$
\begin{gathered}
\tau\left(\lambda_{0}\right)=\beta \lambda_{0}^{-\alpha}, \\
\alpha=-\frac{\ln \left(\tau\left(\lambda_{1}\right) / \tau\left(\lambda_{2}\right)\right)}{\ln \left(\lambda_{1} / \lambda_{2}\right)}, \\
\beta=\frac{\tau\left(\lambda_{1}\right)}{\lambda_{1}^{-\alpha}},
\end{gathered}
$$

where $\tau(\lambda)$ is AOD at the waveband of $\lambda, \alpha$ is the wavelength index, $\beta$ is the Angstrom turbidity coefficient, $\lambda_{1}$ is $550 \mathrm{~nm}$, and $\lambda_{2}$ and $\lambda_{3}$ are the two selected bands closer to 550 , which can be chosen from four bands (440nm, $675 \mathrm{~nm}, 870 \mathrm{~nm}$ and $1020 \mathrm{~nm}$ ).

\subsubsection{AQI}

AQI, defined by the Ministry of Environmental Protection of China, is a dimensionless index to quantitatively describe the status of air quality. The pollutants participating in the AQI evaluation are $\mathrm{PM}_{2.5}, \mathrm{PM}_{10}, \mathrm{SO}_{2}, \mathrm{NO}_{2}, \mathrm{O}_{3}$ and $\mathrm{CO}$. The larger the AQI value, the more serious the air pollution situation and the greater harm to human health. AQI is suitable for indicating the short-term status and changing trends of city air quality. To study the indication effect of MCD19A2 AOD on air pollution, the urban AQI data of BTH region from 2014 to 2018 was selected for correlation analysis with MCD19A2 data.

\section{VERIFICATION OF MCD19A2 AOD}

\subsection{AOD images of MCD19A2}

Figure 2 shows the spatial distribution of four AOD images randomly selected from the MCD19A2 aerosol results, with less cloud cover. The imaging time is 2014/3/16, 2014/8/14, 2014/9/4, 2014/1/3, respectively, distributed in spring, summer, autumn and winter. It shows that MCD19A2 data can provide continuous spatial coverage AOD results under clear sky conditions for BTH region.

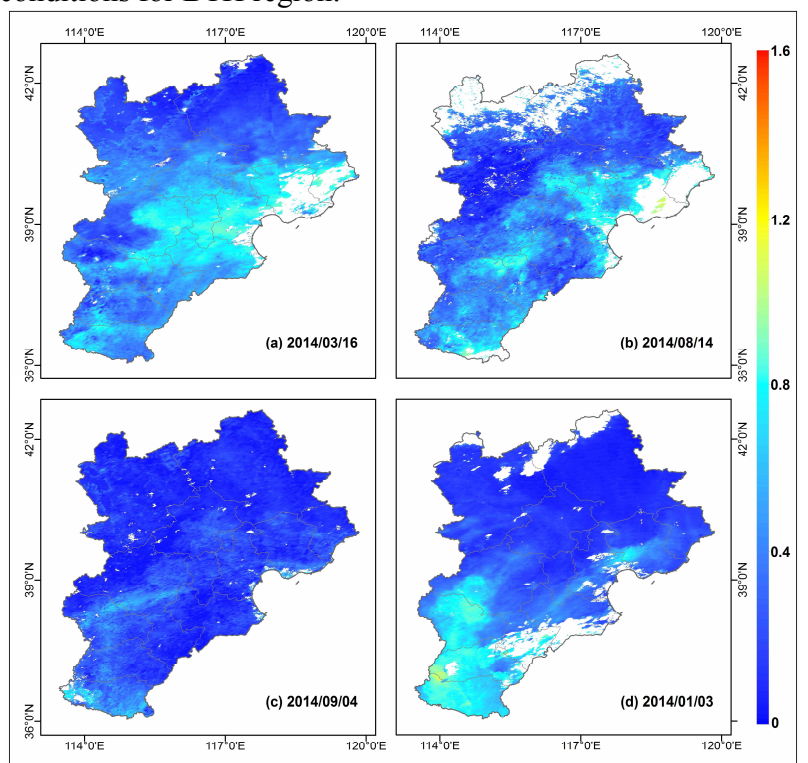

Figure 2. AOD images of MCD19A2 in BTH region

\subsection{Verification with AERONET data}

The AOD measured data of the selected AERONET sites in 2014 was selected to verify the accuracy and applicability of MCD19A2 AOD in BTH region. 
2.2.1 Space-time matching of AERONET and MCD19A2 To ensure the reliability of verification, the AOD data of MCD19A2 and AERONET were accurately matched in time and space. The AERONET AOD at the transit time of the MODIS sensor was taken as the true value. If there was no data at the transit time, the average of AERONET AOD within the range of 30 minutes before and after was taken as the true value. Using a $5 * 5$ pixels sampling window centered on the latitude and longitude of the AERONET site, the average value of the MCD19A2 AOD image was taken as the inversion value.

\subsubsection{The indexes of verification}

Pearson correlation coefficient $(R)$, Relative Mean Bias $(R M B)$, Mean Absolute Error (MAE), Mean Relative Error (MRE), and Root Mean Square Error (RMSE) were selected to quantitatively verify the accuracy of MCD19A2 AOD inversions. At the same time, a linear regression model $(y=k x+b)$ and expected errors $(E E)$ were selected to analyze the overall distribution of the inversion values and true values.

$$
\begin{gathered}
R=\frac{\sum_{i=1}^{n}\left(x_{i}-\bar{x}\right)\left(y_{i}-\bar{y}\right)}{\sqrt{\sum_{i=1}^{n}\left(x_{i}-\bar{x}\right) \sum_{i=1}^{n}\left(y_{i}-\bar{y}\right)},} \\
R M B=\frac{1}{n} \sum_{i=1}^{n} x_{i} / y_{i}, \\
M A E=\frac{1}{n} \sum_{i=1}^{n}\left|x_{i}-y_{i}\right|, \\
M R E=\frac{1}{n} \sum_{i=1}^{n} \frac{\left|x_{i}-y_{i}\right|}{y_{i}}, \\
R M S E=\sqrt{\frac{1}{n} \sum_{i=1}^{n}\left(x_{i}-y_{i}\right)^{2}}, \\
E E= \pm\left(0.05+0.2 \times y_{i}\right),
\end{gathered}
$$

where $x_{i}$ and $y_{i}$ are inversion values and true values, respectively, $\bar{x}$ and $\bar{y}$ are the averages of inversion values and true values, respectively, $n$ is the number of verification point pairs.

\subsubsection{Results and analysis}

Based on the space-time matching method, a total of 698 AOD point pairs of MCD19A2 and AERONET were obtained for verification. Figure 3 shows the scatter distribution of AOD point pairs and the values of the verification indexes.

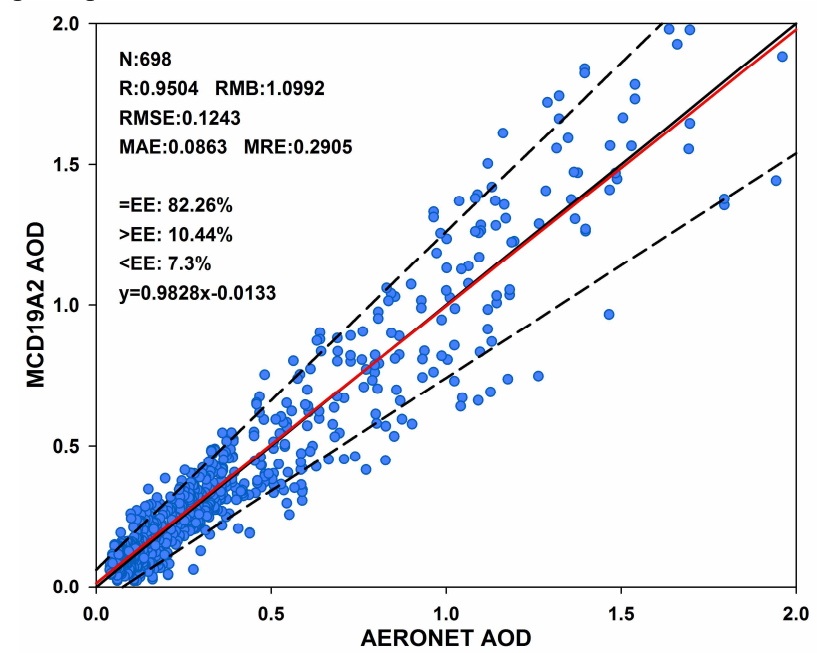

Figure 3. Scatter distribution of AOD point pairs and summary of verification results
MCD19A2 AOD inversions have the small errors ( $R M S E=$ $0.1243, M A E=0.863, M R E=0.2905)$ and a high correlation with the AERONET measured values $(R=0.9504, R M B=1.0992)$. $82.26 \%$ of the inversions fall within the expected error range, indicating that MCD19A2 has high accuracy. As shown in Figure 3, the AOD point pairs are evenly distributed on both sides of the $y=x$ line. The linear regression model has a slope close to $1 \quad(k=0.9828)$ and a small intercept $(b=0.0133)$, indicating that a high consistency of MCD19A2 and AERONET.

The verification results show the high accuracy and reliability of MCD19A2. Therefore, the MCD19A2 data can accurately express the aerosol distribution in $\mathrm{BTH}$ region. It is feasible and reliable to use MCD19A2 for aerosol research and characterization in $\mathrm{BTH}$ region.

\section{STUDY OF AEROSOL CHARACTERISTICS}

The AOD spatial distribution of BTH region from 2014 to 2018 was obtained using the MCD19A2 data. Based on different scales, this article analyzed the aerosol characteristics of BTH region and studied the correlation between AOD and AQI. Figure 4 shows the processing flow of the MCD19A2 data.

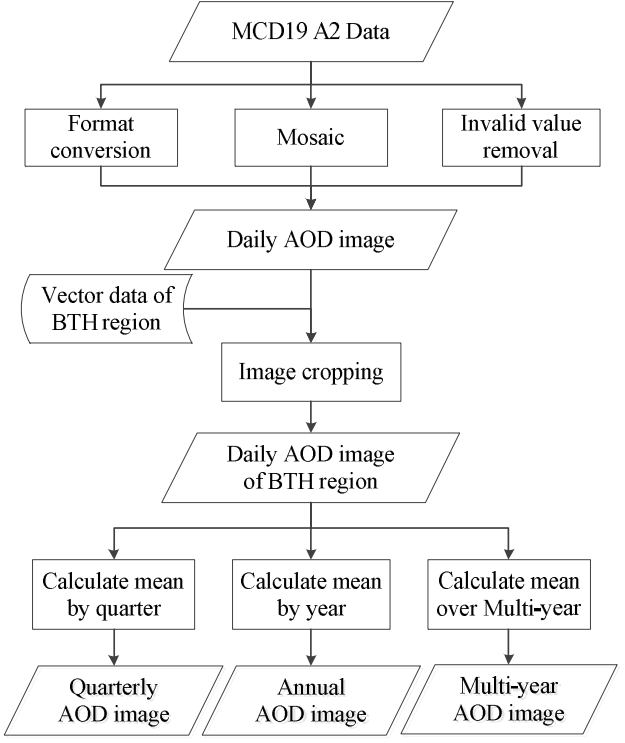

Figure 4. Processing flow of the MCD19A2 data

\subsection{Research on spatial}

The spatial distribution of the AOD multi-year average in BTH region from 2014 to 2018 (Figure 5) was achieved to analyze the aerosol spatial characteristic. The AOD in this region exhibits a spatial distribution characteristic of "high in the south and low in the north, high in the east and low in the west", and shows a gradually increasing trend from the northwest to the southeast (except coastal areas).

At the same time, the AQI data was obtained and compared with the AOD spatial distribution. Based on the monthly average city AQI data of 60 months from 2014 to 2018, the frequency and percentage of different grades were counted, and a histogram (Figure 6) was drawn for a more intuitive display. It is found that the larger the AOD is, the worse the air quality is, and vice versa. The correlation coefficient of AOD and AQI is 0.8339 . These prove that there is a certain correlation between air quality and MCD19A2 AOD. 


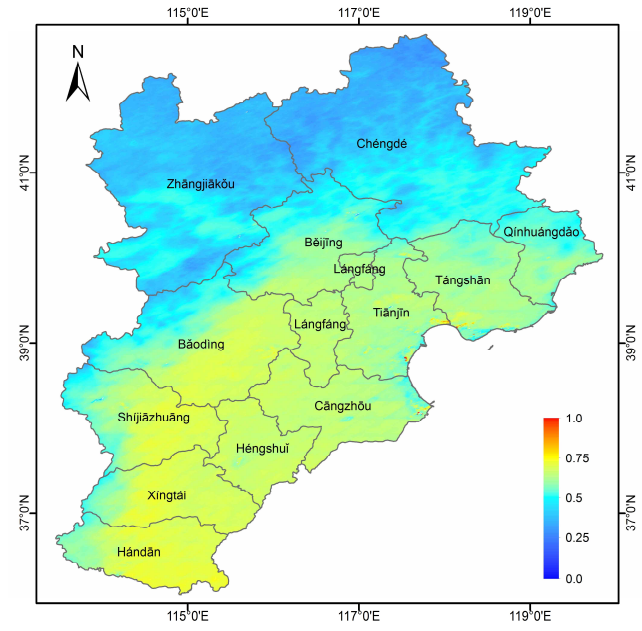

Figure 5. Spatial distribution of AOD multi-year average in BTH region from 2014 to 2018

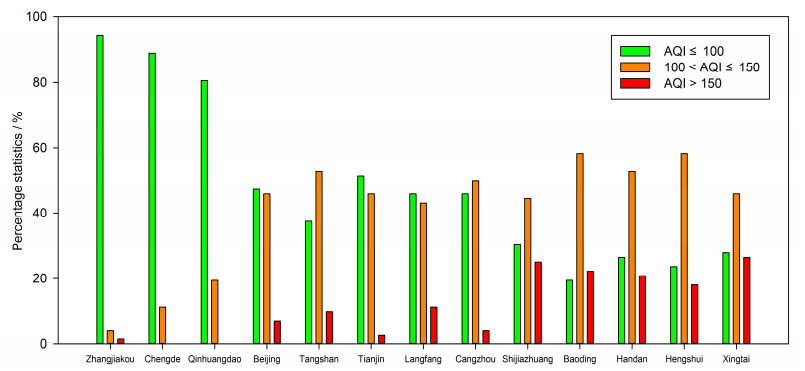

Figure 6. Statistics of urban air quality levels in BTH region from 2014 to 2018

\subsection{Research on time series}

The spatial distribution of the AOD annual averages in BTH region from 2014 to 2018 (Figure 7) was achieved to analyze the inter-annual change trend of AOD. The averages of the AOD annual image from 2014 to 2018 are $0.4557,0.4249$, $0.388,0.3577$ and 0.354 , respectively, which shows a year-onyear downward trend. As shown in Figure 7, the AOD spatial distribution also shows a similar downward trend.

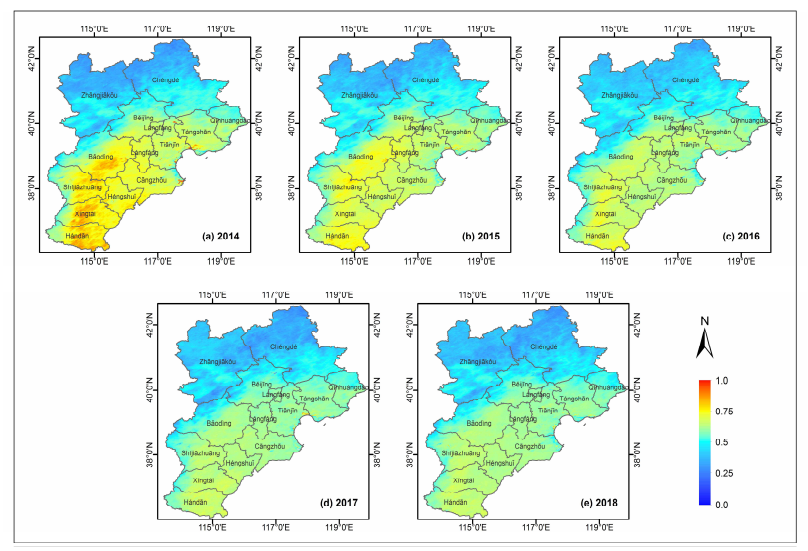

Figure 7. Spatial distribution of AOD annual averages in BTH region from 2014 to 2018

At the same time, the annual average AOD and AQI of 13 cities in BTH region from 2014 to 2018 were obtained to draw the polylines of them with the year (Figure 8). The year-to-year changes in AOD and AQI of different cities are consistent, and the correlation coefficient of AOD and AQI is 0.8145, which proves the certain correlation between air quality and MCD19A2 AOD.

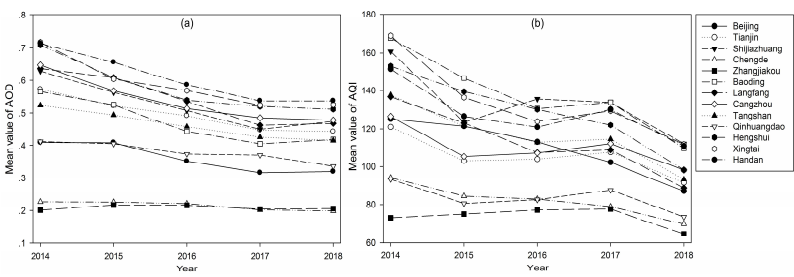

Figure 8. Annual averages AOD and AQI of 13 cities in BTH region from 2014 to 2018

\subsection{Research on season}

The spatial distribution of the AOD seasonal averages in BTH region from 2014 to 2018 (Figure 9) was achieved to analyze the aerosol variation characteristics in different seasons. The AOD seasonal averages in spring (March to May), summer (June to August), autumn (September to November) and winter (November, December, and January) are 0.4234, 0.5181, 0.3584 , and 0.2944 , respectively. The averages and spatial distribution exhibit the seasonal characteristics that AOD is relatively high in spring and summer and relatively low in autumn and winter.

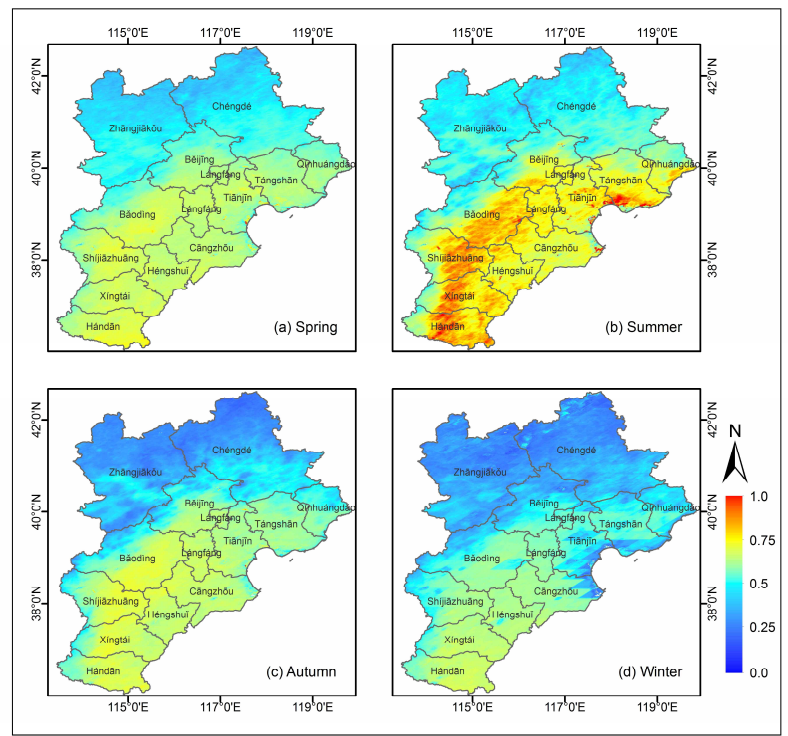

Figure 9. Spatial distribution of AOD seasonal averages in BTH region from 2014 to 2018

\section{CONCLUSION}

This article verified the MCD19A2 aerosol product and studied the aerosol characteristics in BTH region. First, the AERONET measured data was used to verify the MCD19A2 product, which proved the high accuracy and reliability of MCD19A2 AOD. The verifications also proved that MCD19A2 can accurately express the aerosol distribution in $\mathrm{BTH}$ region. Then the MCD19A2 data was used to analyze the aerosol characteristics in the BTH region. Besides, the correlation between AOD and AQI was studied to prove the direct indication of MCD19A2 on air pollution. This article provides relevant references for aerosol research and characterization in BTH region, and plays an important role in environmental issues such as aerosol pollution monitoring, air quality assessment. 


\section{ACKNOWLEDGEMENTS}

The authors thank NASA (https://www.nasa.gov/) for providing MCD19 aerosol product data, and also thank AERONET (https://aeronet.gsfc.nasa.gov/) for providing aerosol groundbased observation data.

This work was supported by the National Natural Science Foundation of China (41771408) and the Shandong Provincial Natural Science Foundation, China (ZR201702210379).

\section{REFERENCES}

Bei, N., Zhao, L., Wu, J., Li, X., Feng, T., Li, G., 2018. Impacts of sea-land and mountain-valley circulations on the air pollution in Beijing-Tianjin-Hebei (BTH): A case study. Environmental Pollution, 234, 429-438.

Bilal, M., Nichol, J. E., Nazeer, M., 2016. Validation of AquaMODIS C051 and C006 Operational Aerosol Products Using AERONET Measurements Over Pakistan. IEEE Journal of Selected Topics in Applied Earth Observations and Remote Sensing, 9(5), 2074-2080.

Charlson, R. J., Schwartz, S. E., Hales, J. M., Cess, R. D., Coakley, J. J., Hansen, J. E., Hofmann, D. J., 1992. Climate forcing by anthropogenic aerosols. Science, 255(5043): 423430.

Chudnovsky, A., Tang, C., Lyapustin, A., Wang, Y., Schwartz, J., Koutrakis, P., 2013. A critical assessment of high-resolution aerosol optical depth retrievals for fine particulate matter predictions. Atmospheric Chemistry and Physics, 13(21), 10907-10917.

Kaufman, Y. J., Sendra, C., 1988. Algorithm for automatic atmospheric corrections to visible and near-IR satellite imagery. International Journal of Remote Sensing, 9(8): 1357-1381.

Lyapustin, A., Wang, Y., Frey, R., 2008. An automatic cloud mask algorithm based on time series of MODIS measurements. Journal of Geophysical Research, 113(D16).

Lyapustin, A., Tedesco, M., Wang, Y., Aoki, T., Hori, M., Kokhanovsky, A., 2009. Retrieval of snow grain size over Greenland from MODIS. Remote Sensing of Environment, 113(9), 1976-1987.

Lyapustin, A., Wang, Y., Laszlo, I., Kahn, R., Korkin, S., Remer, L., Levy, R. C., Reid, J. S., 2011. Multiangle implementation of atmospheric correction (MAIAC): 2. Aerosol algorithm. Journal of Geophysical Research: Atmospheres, 116(D3).

Sayer, A. M., Munchak, L. A., Hsu, N. C., Levy, R. C., Bettenhausen, C., Jeong, M. J., 2014. MODIS Collection 6 aerosol products: Comparison between Aqua's e - Deep Blue, Dark Target, and "merged" data sets, and usage recommendations. Journal of Geophysical Research: Atmospheres, 119(24): 13,965-13,989.

Sokolik, I. N., Toon, O. B., 1996. Direct radiative forcing by anthropogenic airborne mineral aerosols. Nature, 381(6584): 681.
Xie, Y., Zhang, Y., Xiong, X., Qu, J. J., Che, H., 2011. Validation of MODIS aerosol optical depth product over China using CARSNET measurements. Atmospheric Environment, 45(33), 5970-5978.

Wang, G., Cheng, S., Li, J., Lang, J., Wen, W., Yang, X., Tian, L., 2015. Source apportionment and seasonal variation of PM2.5 carbonaceous aerosol in the Beijing-Tianjin-Hebei Region of China. Environmental Monitoring and Assessment, $187(3), 143$.

Wang, L., Zhang, F., Pilot, E., Yu, J., Nie, C., Holdaway, J., Yang L., Li Y., Wang W., Vardoulakis S., Krafft, T., 2018. Taking Action on Air Pollution Control in the Beijing-TianjinHebei (BTH) Region: Progress, Challenges and Opportunities. International Journal of Environmental Research and Public Health, 15(2), 306.

Wei, J., Sun, L., 2016. Comparison and evaluation of different MODIS aerosol optical depth products over the BeijingTianjin-Hebei region in China. IEEE Journal of Selected Topics in Applied Earth Observations and Remote Sensing, 10(3): 835844.

Wong, M. S., Shahzad, M. I., Nichol, J. E., Lee, K. H., Chan, P. W., 2013. Validation of MODIS, MISR, OMI, and CALIPSO aerosol optical thickness using ground-based sunphotometers in Hong Kong. International Journal of Remote Sensing, 34(3), 897-918. 